\title{
Appreciation on Figures of Speech of Once More to the Lake
}

\author{
Guiying Kong \\ International Exchange College \\ Wuzhou University \\ Wuzhou, China 543002
}

\begin{abstract}
Rhetoric is an art of linguistic performance. Using them properly can enhance the effect of expression, vividness, persuasiveness and appeal of language. There are a lot of elegant figures of speech in Once More to the Lake, the article will appreciate their usages from the perspective of phonetics, semantics, syntax so as to provide further help and reference for the readers' appreciation.
\end{abstract}

Keywords-Once More to the Lake; figures of speech; appreciation

\section{INTRODUCTION}

English figures of speech refer to the technique of using various linguistic ways to improve the expressive methods of language in the works, which has the effects of deepening, beautifying, strengthening the language expression and appeal, it is a language art of realization to unite the words and aesthetic value [1]. Rhetoric is different from the direct statement and expression of the surface words, which has more meanings than ordinary surface words or literal sense. In general, rhetoric can be classified into three categories: phonological rhetorical devices, semantic rhetorical devices, syntactical rhetorical devices. If the author uses properly figures of speech in his works, it could heighten artistic expression and appeal of the works. Because the works' language will become more vivid, image is more specific, content is more profound, rhythm is brighter, vigor is stronger than before, at the same time, it will stimulate the readers' endless imagination and enjoy the works' artistic conception.

“Advanced English I" Edited by College of Foreign Languages of Naikai University and published by Naikai University Press is widely used for English majors in colleges and universities in which has many rhetorical uses in the good works. Once More to the Lake is one of the best works written by Elwyn Brooks White, a contemporary essay writer in USA. The essay described the story that the

The paper is:

1. Major project of Wuzhou university-level scientific research in 2016: "The Study on Artistic Conception and Figures of Speech of Once More to the Lake", project number: 2016B011.

2. Phase result of the key research base on humanities \& social sciences in Guangxi universities-The Research Center of Folk Literature in Xijiang River, (project number: Guangxi Educational Scientific Research [2014] 12).

3. Funded by "Youth Backbone Teachers' Training Program" of Wuzhou University.
Whites went vacation to the lake in the woods in Maine Although time passed many years, the lake's natural landscape was still beautiful, quiet without any change which made White compare the lake scenes today with its past memories frequently, and produced nostalgic feelings continuously of from this. Apparently, the essay depicted the beauty of the lake, but it actually depicted deeply white's nostalgia. It was worth mentioning that White observed the lake scenes very meticulously, his writing was exquisite, and different categories of rhetoric White used in this essay were perfect, even better, some kinds of figures of speech were using in a sentence group. With the help of rhetoric, White described the lake more beauty and placidity. It was worth thinking deeply for us of the theme that White created an artistic conception: "Time was gone, the continuation of generations and inheritance were inevitable". Next, we will appreciate how White uses the figures of speech one by one in the essay.

\section{Phonological RHETORICAL DEVICES}

English phonological rhetoric devices are the methods that using the articulate characteristics of the words, sentences to create sound rhetoric which can make the language in the essay has more power, vivid expression and appeal. Their rhythms have the readable characteristics of aesthetic perception of ups and downs, cadence including onomatopoeia, alliteration, assonance, etc. In addition, diphthongs, long vowels, stressed syllables, rhythms and -ing forms can also achieve a certain degree of effect. In Once More to the Lake, White made full use of the characteristics of long vowels, diphthongs, consonants, consonants letters, stressed syllables to emphasize the rhythms, these rhythms not only conveyed the writer's feeling and ideas, but heightened the beauty of music and melody, what's more, they could achieve the harmony between words' meanings and effect of rhythms.

\section{A. Onomatopoeia}

Onomatopoeia refers to imitate the sounds of the natural non-language, which are similar to the sounds of the things or actions described. They can make the language vivid and expressive. For example 1: 
Example 1: The one-lungers throbbed and fluttered, and the twin-cylinder ones purred and purred; and that was a quiet sound too ${ }^{1}$. (para.10)

Throb referred to the sound of "throbbing, rumbling", flutter meant the sound of "swing, wings", purr was also "purr, grunt" sound. White used these sounds to describe the sound of one-lungers, twin-cylinder on a yacht, showing the language vivid and expressive. Here, White wanted to use some tedious onomatopoetic words to reveal the voice of the yacht so dull and boring which had a great incompatible with the quiet and beautiful atmosphere of the lake, under such contrast, Which would sigh and remember the things that he could do with the old one-cylinder engine with the heavy flywheel.

\section{B. Long Vowels, Diphthongs, Consonant Letters}

The pronunciation of English long vowels, diphthongs are usually loud, clear and melodious, and their rhythms are relatively gentle which highlight the characteristics of things. Short vowels, consonants, consonants letters are read fast, shortly and softly, so their rhythms are relatively brisk and lively. For example 2:

Example 2: ......There are days when the restlessness of the tides and the fearful cold of the sea water and the incessant wind that blows across the afternoon and into the evening make me wish for the placidity of a lake in the woods. (para.1)

In example 2, White combined the content words of long vowels (bold mark) sea, water, evening, afternoon, me with the content words of diphthongs (bold mark) there, day, tide, fearful, cold, blow, make, lake, and with the aid of consonants letters (underlining) blow, across, placidity, the complete sentence was staggered and paralleled by long, dual, short vowels with consonants letters, which sometimes read highly and loudly, sometimes fast and softly, it could show the musical aesthetic perception of lightness, stress, slowness, quietness, ups and downs, cadence[2]. The phonological rhythm here perfectly decorated the scenes which White wrote, the readers can't help feeling white's emotion to the lake through these phonological rhythms, and feelings the restlessness of the tides, the fearful cold of the sea water, the incessant wind blowing from the afternoon to the evening.

\section{The Rhythm of Consonants, Short Vowels, Parallelism, Onomatopoeia}

The rhythm mainly uses pause to embody, its length forms the different rhythms and also becomes different rhyme effect. There is a direct relationship of the pause on the formation of consonants, short vowels, long sentences, short sentences, and repetition, parallelism. Such as in example 3, White used skillfully the rhythms of consonants, short vowels and rhetorical rhythm of parallelism, onomatopoeia to quicken the rhythm for creating nervous atmosphere. The original sentence combined by rhetoric of

1 Note: The examples in this article are selected from "Advanced English I" Edited by College of Foreign Languages of Naikai University and published by Naikai University Press, Unit 3 Once More to the Lake. parallelism and onomatopoeia, grammatical pause and nongrammatical pause was intermittent evenly, coherent and was formed a sentence pattern with natural, beautiful and rich rhythm.

Example 3: Then the kettle drum, then snare, then the bass drum and cymbals, then crackling light against the dark, and the gods grinning and licking their chops in the hills. (para.12)

In example 3, White used four "then + noun" structures making up a parallelism which speeded up the tense atmosphere of the continuous thunder. The relative concentration of the plosive $\mathrm{k}, \mathrm{t}, \mathrm{d}, \mathrm{b}, \mathrm{p}$ in notional words also created a fast rhythm, the short and loud vowels such as e, i, o also played a faster role. The onomatopoeia of musical instruments drum, snare, cymbals, crackling substitutes the sound of thunder, which having the effect of speeding up the pace, also strengthening the impression. The sharp contrast between the violent scenes of thunder lightning and the quiet lake brought the readers psychological echo, and highlighted the exuberant vitality of nature. Overall, White comprehended the feature of English rhythm, combined skillfully these sounds and words, depicted vividly a process of thunder, lightning and thunderstorm, which gave the readers a feeling of actually being there[3].

\section{Stressed Syllable}

Stressed syllable is another important method of English phonological rhetoric. The readers are also pleasant to read, because the stressed syllables are usually loud and clear, easy to attract the readers' full attention to emphasize the effect. The clever collocation of stressed syllables and unstressed syllables can also be formed the rhythmic beauty of ups and downs and cadences [4].

Example 4: Summertime, oh, summertime, pattern of life indelible, the fadeproof lake, the woods unshatterable, the pasture with the sweet fern and the juniper forever and ever, summer without end. (para.8)

In example 4, syllables (bold mark) and stressed monosyllable: life, lake, woods, sweet (underlining) with unstressed syllable words collocate in this sentence which reads having the features of light and stress, ups and downs, cadence, etc. The rhythm of the stressed and unstressed syllables highlights White's sad nostalgia. When reading, the readers can taste carefully White's endless sentiment and nostalgic feeling to the lake life of today and past from the rhyme beat of light or stress, strong or weak: lake, woods, sweet fern and the juniper are still the same, forever and ever, time stops, and syntactical rhetorical devices.

\section{SEMANTIC RHETORICAL DEVICES}

English semantic rhetorical devices mainly use the change of semantic association and language change to create rhetoric, a word or phrase diverges from normal meaning or literal meaning in which case the word or phrase is said to be used figuratively and convey meanings in a vivid and impressive manner [5]. In this essay, White uses semantic rhetoric, such as simile, metaphor, and personification. 


\section{A. Simile}

English simile is a figure of speech that makes a comparison between two dissimilar things having certain qualities or characteristics in common and usually consists of tenor, vehicle and indicator of resemblance [6]. In general, simile compares different things in common which existing in human's psychology, rather than the nature things, thus more vividly explain or image things to realize an impressive effect. In example 5, White compared "new engine sound (they)" (tenor) to the sounds of mosquitoes (vehicle), buzzing and vivid.

Example 5: At night, in the still evening when the afterglow lit the water, they whined about one's ears like mosquitoes. (para.5)

In example 6, White with his child met a thunderstorm (it), white compared " the thunderstorm" to the ancient "melodrama", whether" the thunderstorm" or "the melodrama", White had a common psychology for them, that was fear, this simile gave the readers deep impression.

Example 6: It was like the revival of an old melodrama that I had seen long ago with childish awe. (para.12)

\section{B. Metaphor}

Metaphor is a figure of speech often used to describe A as an abject of B without using indicator of resemblance of "like" or "as", which indicates directly that A is B to enhance the expressive force of language. In example 7, White regarded the voice of the old engine as sedative of summer sleep, and the sound of new engine compared to mosquito in sharp contrast to the annoying buzzing sound, expresses indirectly his nostalgia to the past and his missing to his father.

Example 7: ... all motors were inboard...the noise they made was a sedative, an ingredient of summer sleep. They were one-cylinder and two-cylinder engines, and some were make-and-break and some were jump-spark, but they all made a sleepy sound across the lake. (para.7)

In example 8, White described "thunderstorm" as the second-act climax of the drama, which was apt and figurative to highlight the expression.

Example 8: It was like the revival of an old melodrama ...... The second-act climax of the drama of the electrical disturbance over a lake in America had not changed in any important respect. (para.12)

\section{Personification}

It is a figure of speech that gives inanimate object human form of feelings, qualities or abilities to achieve vivid description of things and express deeply the purpose of emotion. Personification often endows things with human and animals which make the readers feel vivid and interesting when they read. White also used many personified rhetoric making the language vivid in this essay. For example 9:

Example 9: This seemed an utterly enchanted sea, this lake you could leave to its own devices for a few hours and come back to, and find that it had not stirred, this constant and trustworthy body of water. (para.6)

"leave to its own devices" could be understood as "let go of its own way, let it go". White here anthropomorphized the lake, highlighted the intimacy between human and nature. In example 10, the verb "whined" generally referred to a person's "cry, complain tearfully", White used it on the engine which gave the characteristics of life so as to make the sentence more vivid.

Example 10: In the daytime, in the hot mornings, these motors made a petulant, irritable sound; at night, in the still evening when the afterglow lit the water, they whined about one's ears like mosquitoes. (para.10)

In example 11, White gave "the boat" a life's character, and regarded it as a mad cow with its quick and foolhardy movements, adding to the freshness and vividness of the sentences. Again, in example 12, White personified the moment of the lightning as grinning and licking of the gods which more vividly depicted the thunderstorm scenes.

Example 11: ... and the boat would leap ahead, charging bull-fashion at the dock. (para.10)

Example 12: ... and the gods grinning and licking their chops in the hills. (para.12)

\section{Syntactical RHETORICAL DEVICES}

Syntactical rhetorical devices mainly refer to the rhetorical devices created by the balanced layout of the sentence structure or prominent emphasis. What White combined the subtlety with the repetition and parallelism in this essay was to enhance the infection of language expression, to foil the artistic conception and to achieve the purpose of sublimation.

\section{A. Repetition}

Repetition has a strong infection and persuasion which can make semantic focus, thorough reasons, it can not only reinforce the sense of rhythm and the melody beauty, but make it easy for the readers to understand the connotation of the sentences to realize the effect of emphasis. It can be said that in Once More to the Lake, White used it to the extreme, such as in example 13, the repetition strongly demonstrated a deep memory of the past, White deeply remembered: time has passed many years, but in his heart everything never changed, even his feeling as before. The same (underlining) repeated five times emphasizing the nostalgic semantic meaning, vivid rhythm made the readers feel the past days again, all things were eternal, time never passed.

Example 13: The small waves were the same, .......and the boat was the same boat, the same color green and the ribs broken in the same places, and under the floor-boards the same freshwater leavings and ......from yesterday's catch. (para.5)

In example 14-16, the sentence "There had been no years (underlining)" repeats three times which was the regretful core of White, what White used here was to build a perversion of time-space of the artistic conception, the lake scenes were still the same in the eyes, but the years has 
passed. White's nostalgic feeling here reflected incisively and vividly, the readers can't help following White to open their train of thought again to imagine the scenes and the objects of the lake for getting the enlightenment and edification, simultaneously, they would think the theme positively about the ephemeral life and existing eternity [7].

Example 14: Everything was as it always had been, that the years were a mirage and that there had been no years. (para.5)

Example 15: There had been no years between the ducking of this dragonfly and the other one - the one that was part of memory. (para.5)

Example 16: Over the years there had been this person with the cake of soap ... here he was. There had been no years. (para.6)

\section{B. Parallelism}

Parallelism, also known as parallel structure, refers to two or more similar or the same structures, which have equal significance, coherent tone in phrases and sentences arranged in series to form an integral rhetoric. Parallelism has such characteristics: certain structural symmetry, smooth tone, prominent emphasis, which is easy to make the sentence rhythmic beauty, and help the author express strong feeling and strengthen persuasion. White also used many parallelisms in this essay which gave a strong brushstroke for the elegant essay. Such as in previous example 3, "then + noun" parallel structure, and example 4 , the parallelism was composed of "noun + phrase" detailing a description on the lake sceneries and revealing the beauty of nature, which not only could make the readers appreciate the symmetric harmonious structure, but could enter the quiet, poetic water of the lake.

Example 17: ......you can remember about places like ......return into the grooves which lead back. You remember one thing ... reminds you of another thing. I guess I remembered clearest of ... I remembered being very careful never to rub my paddle ... disturbing the stillness of the cathedral. (para.2)

In example 17: White used several "remember (underlining)" to emphasize his memory of the past. White remembered that "the bedroom smelled the scent of lumber", "sneak out into the sweet outdoors", "keeping close along the shore", "very careful never to rub my paddle against the gunwale"....., following the "remember" steps, as vivid as the picture, the readers would deeply feel that everything was quiet at that night, White moved on with great care for fear of disturbing the stillness of the cathedral.

Example 18: I would be in the middle of some simple act, I would be picking up a bait box or laying down a table fork, or I would be saying something, and suddenly it would be not I but my father who was saying the words or making the gesture. It gave me a creepy sensation. (para.4)

In Example 18, "I would be (underlining)", White used three times which strongly expressed the absentminded feeling of White to time-space interweaving, and the sense of ambiguity and gap between reality and memory. White turned his present movements to the past, the true or false of the scenes between the present and the past expresses intensely his nostalgia. Again, In Example 19, parallelism was consisted of "subject + verb" structures (underlining), roughly equal length sentences were put together and formed structural symmetry, compact coordination, harmonious rhythm, which foiled the hot atmosphere in summer, greatly strengthened the expressive force of language.

Example 19: the tape had loosened along the backline, the alleys were green with plantains and other weeds, and the net (installed in June and removed in September) sagged in the dry noon, and the whole place steamed with midday heat and hunger and emptiness. (para.7)

Example 20: ... and the campers running out in joy and relief to go swimming in the rain, their bright cries perpetuating the deathless joke about how they were getting simply drenched, and the children screaming with delight at the new sensation of bathing in the rain, and the joke about getting drenched linking the generations in a strong indestructible chain. (para.12)

And again, in example 20, "noun + present participle" structures (underlining) formed a parallelism, removed "were" among them, which formed the lilting rhythms, vividly embodied the process that the mood of the campers saw the rain from nervousness, excitement to relaxation, easiness.

\section{CONCLUSION}

To sum up, White has used a lot of phonological, semantic, syntactic rhetorical devices in this essay. These rhetorical devices were accurate use, graceful structure; their expressions were fresh, vivid, imagined which made the sentences have more profound meanings, artistic conception was far-reaching. The rhetorical devices here also gave much highlight on writing which embodying the excellent, flexible control ability of English writing of White.

Through the rhetoric appreciation and analysis of this essay, we can not only further understand the writing style and rhetoric skill of White, but can also further understand the inside meanings of sentences, and therefore to get the theme of the artistic conception which White conveyed. What's more, during the process of rhetorical appreciation, the readers can gradually broaden their English cultural vision; improve their appreciating ability and aesthetic taste to English essay.

\section{REFERENCES}

[1] Lv Xu. Practical English for Rhetoric [M]. Beijing: Tsinghua University Press, 2011:124.

[2] Kong Guiying. The artistic Conception of the Scene and Melodic Rhetoric of Once More to the Lake[J]. The Great Wall, 2011(6): 168159.

[3] Chen Yannan. The rhythm and the translation of Once More to the Lake[J]. Crazy English (for teachers), 2011(4) 186-187.

[4] Qin Xiubai. The Stylistics [M]. Changsha: Hunan Education Press, 1987: 27.

[5] http://en.wikipedia.org/wiki/Figure_of_speech. 
[6] http://www.doc88.com/p-667157480907.html.

[7] Kong Guiying. The artistic Conception of the Scene and Melodic Rhetoric of Once More to the Lake[J]. The Great Wall, 2011(6): 168159. 